\title{
Functionalized calix[4]pyrroles
}

Jonathan L. Sessler*, Pavel Anzenbacher, Jr., Karolina Jursíková, Hidekazu Miyaji, John W. Genge, Nicolai A. Tvermoes, William E. Allen, and James A. Shriver

Department of Chemistry \& Biochemistry, The University of Texas at Austin, Austin, TX 78712 USA

Philip A. Gale

Chemistry Department, University of Oxford, Inorganic Chemistry Laboratory, South Parks Road, Oxford, OXI $3 Q R, U K$.

Vladimír Král

Department of Analytical Chemistry, Institute of Chemical Technology, 16628 Prague 6, Technická 5, Czech Republic

Abstract: The synthesis and properties of a number of functionalized calix[4]pyrroles are described. To date, two generalized preparative approaches have been pursued. The first involves modifying the basic pyrrole-plus-ketone synthesis of calix [4]pyrrole by using modified precursors or by co-condensing more than one ketone with pyrrole. The second approach relies on the reaction of a pre-formed calix[4]pyrrole with an electrophile. In both cases, the resulting species can be subject to further manipulation. In this way a range of structures, including ones bearing ancillary recognition subunits, electro- or photochemical reporter groups, and/or water solubilizing substituents may be obtained. Solid supports bearing calix[4]pyrroles may also be produced in this way.

\section{INTRODUCTION}

The field of anion binding chemistry, while far less developed than that of cation chelation, is currently viewed as being one of the important frontiers in the generalized area of supramolecular chemistry and molecular recognition. Much of this emphasis derives from an appreciation that appropriately designed anion receptors have critical roles to play in the development of fluorescent sensors, ${ }^{1}$ electrochemical signaling devices, ${ }^{2}$ and ion selective electrodes. ${ }^{3}$ It is also appreciated that anion recognition subunits, perhaps site-isolated on solid supports, might prove useful in the areas of waste remediation ${ }^{4}$ and charged substrate separation.5,6 Finally, while less widely disseminated, it is slowly becoming recognized that biocompatible anion carriers could hold the key to the development of new treatments for cystic fibrosis and AIDS.7,8

Given their importance, it is not surprising that a number of groups, including our own, are devoting considerable effort to the task of generating new anion binding receptors. Here, much of the current focus is on generating systems that are not only easy to prepare but also easily tuned in terms of their inherent anion binding characteristics. ${ }^{9}$ One system that appears particularly attractive in this regard, and the subject of this report, is calix[4]pyrrole (e.g. 1 and 2). ${ }^{10}$ It is simple to

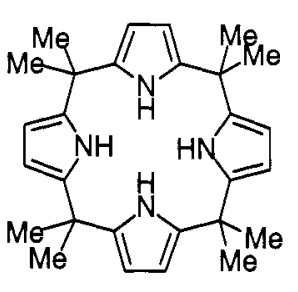

1

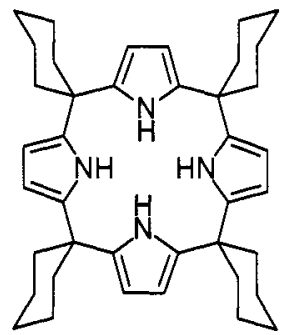

2 prepare and easy to functionalize.

*Lecture presented at the 1st International Conference on Supramolecular Science and Technology, Zakopane, Poland, 27 September-3 October 1998.

Other presentations are published in this issue, pp. 2337-2408. 
The calix[4]pyrrole are a most venerable class of materials. They were first prepared by Baeyer in $1886^{11}$ but only recently recognized for their anion binding potential. ${ }^{10,12}$ In the case of the simple, octaalkyl functionalized systems 1 and 2 , it was found that both fluoride and chloride anion were bound in the solid state and that these two anions, and to lesser extent dihydrogen phosphate, are bound in dichloromethane solution (for 1 : $K_{\mathrm{a}}=17,000,350$, and $100 \mathrm{M}^{-1}$ for $\mathrm{F}^{-}, \mathrm{Cl}^{-}$, and $\mathrm{H}_{2} \mathrm{PO}_{4}{ }^{-}$, respectively). ${ }^{12}$ Shortly thereafter, it was discovered that calixpyrroles bind neutral substrates, albeit weakly. ${ }^{13}$ Efforts then turned immediately to the problem of preparing functionalized calix[4]pyrroles and the related task of obtaining systems whose inherent anion binding properties were modified relative to the "parent" systems 1 and 2. These studies, while still ongoing, are beginning to provide much in the way of structure-function insight.

\section{FUNCTIONALIZATION EFFECTED $V I A$ DIRECT CONDENSATIONS}

\section{Simple Homo-condensations Involving a Single Ketone and a Single Pyrrole}

Perhaps the most appealing feature of calix[4]pyrrole chemistry is the fact that systems such as 1 and 2, bearing identical alkyl substituents in all eight of the meso-like positions, are incredibly easy to make. All one needs to do is to condense a ketone with pyrrole under conditions of acid catalysis. In this way one can isolate systems such as $\mathbf{1}$ and $\mathbf{2}$ in upwards of $60 \%$ yield. Appreciating this, we have prepared a whole range of elaborated systems, including 3-13, whose existence is predicated on the use of an appropriately functionalized pyrrole and/or ketone. ${ }^{10,12-16}$ While many of these systems have yet to be studied in detail, it is already becoming apparent that the basic anion binding characteristics of the calix[4]pyrrole skeleton are indeed affected by the number and type of substituents present on the mesolike bridges and'or $\beta$-pyrrolic sites (vide infra).

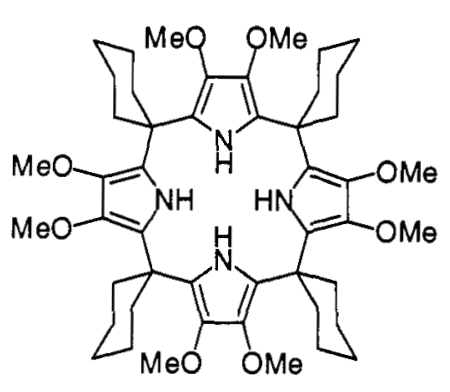

3

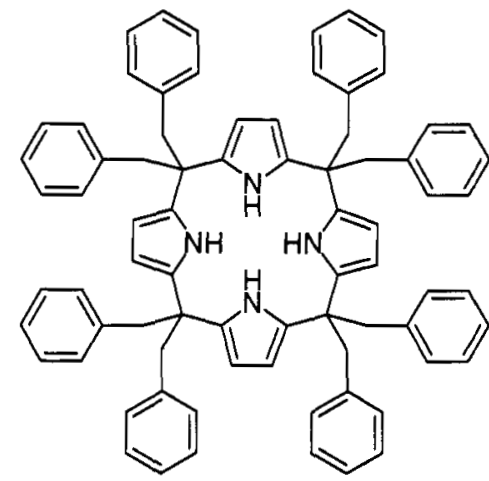

4

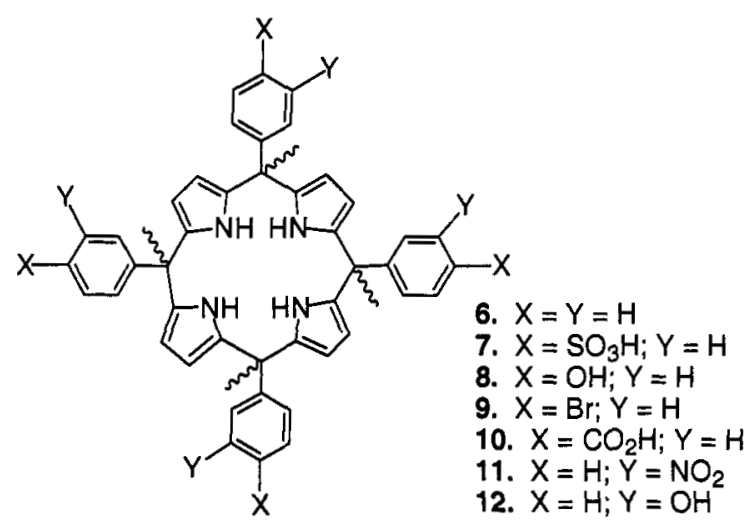<smiles>OCC(CO)(CO)c1ccc(C(CO)(CO)c2ccc(C(CO)(CO)c3ccc(C(CO)(CO)c4ccc(C(CO)(CO)CO)[nH]4)[nH]3)[nH]2)[nH]1</smiles>

5 
Among the collection of products 3-13, the octamethoxy derivative 3 stands out as being particularly important. This derivative, prepared early on in our efforts to map out the basic anion binding characteristics of the calix[4]pyrroles, was found to be a far weaker fluoride anion binder (by a factor of 50) than the parent system $2 .{ }^{14}$ This led to the consideration that the synthetic "addition" of $\pi$ electron withdrawing groups, as opposed to $\pi$-donating methoxy substituents, in the $\beta$-pyrrolic positions would lead to enhanced anion binding affinity. As detailed below, this approach did work in terms of effecting the desired binding constant enhancements. Unfortunately, the systems in question proved difficult to prepare using a direct pyrrole-plus-ketone condensation approach. They could, however, be obtained via a post-synthetic modification process as described later on in this report.

Another generalized set of systems obtainable from direct homo-condensations of ketones and pyrroles are meso-alkyl and meso-aryl substituted calix[4]pyrroles. This class of products differs from simple $\beta$-pyrrole substituted calix[4]pyrroles in that the substituents need not only point out away from the macrocyclic core. They can thus influence anion binding affinities via a combination of electronic and steric effects. Further, they can affect the basic conformational properties of the calix[4]pyrrole core and thus control the spatial orientation (and availability) of the various pyrrolic $\mathrm{NH}$ donor groups that might, or might not, be involved in anion binding. On a more pragmatic level, just as is true for the purely $\beta$ pyrrole substituted systems, the meso substituents may be chosen so as to achieve a desirable set of molecular characteristics, such as water solubility, membrane or liposomal affinity, and increased (or reduced) anion binding affinity.

The octahydroxy calix[4]pyrrole 5 stands as a nice illustration of the above point. This material, obtainable from dihydroxyacetone dimer and pyrrole via either a direct condensation or through the use of acetate protected intermediates, displays appreciable water solubility. It is thus likely to prove useful when it comes to studying the properties of calix[4]pyrroles in aqueous and biological milieus. This particular end use utility is also expected to be manifest in the case of the tetrasulfonate derivative 7 . This system, although difficult to isolate cleanly, shows high water solubility over a wide range of $\mathrm{pH}$. Good water solubility, especially at higher $\mathrm{pH}$, is also observed for the carboxyl substituted congener 10. Meanwhile, analogue 8 was been found to dissolve nicely in mixtures of water and alcohol.

One of the reasons that the solubilized systems 7,8 , and $\mathbf{1 0}$ are difficult to obtain in clean form is that they, like calix[4]pyrroles $6,9,11-13$, are actually formed as a mixture of configuration isomers (c.f. Figure 1). In the case of $\mathbf{8 , 9}$, and $\mathbf{1 3}$, these different isomers have been separated from one another and found to display, interestingly enough, differing relative anion binding affinities. In the particular case of 9 , the $\alpha \alpha \beta \beta$ isomer was found to possess an unusually high affinity towards fluoride anion $\left(K_{\mathrm{a}} \geq 10^{5} \mathrm{M}^{-1}\right.$ in $\mathrm{CD}_{2} \mathrm{Cl}_{2}$ ) as well as an avidity for chloride anion that is increased by a factor of roughly 3-5 relative to 1 . By contrast, the less symmetric $\alpha \alpha \alpha \beta$ isomer of 9 displays binding constants for both these anions that, while still larger than those of 1 , are considerably less enhanced. Taken together, these results serve to illustrate just how important slight deviations in structure can be in terms of fine-tuning the anion binding properties of a given calix[4]pyrrole-type receptor system.

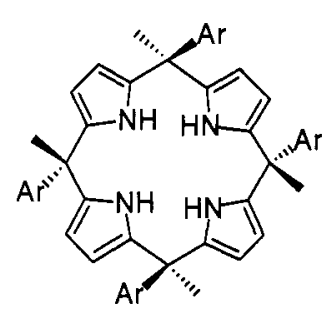

$\alpha \beta \alpha \beta$

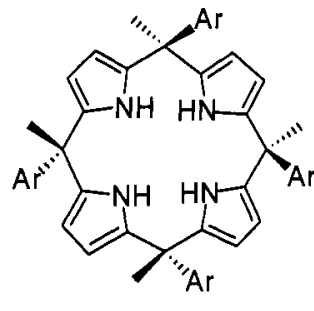

$\alpha \alpha \beta \beta$

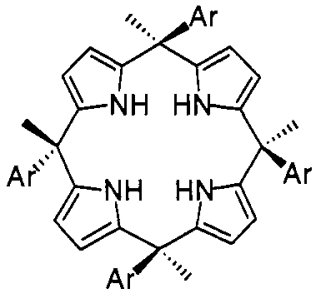

$\alpha \alpha \alpha \beta$

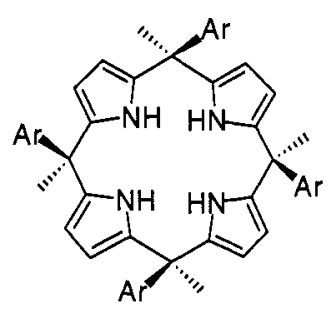

$\alpha \alpha \alpha \alpha$

Figure 1. Possible isomers of meso-substituted tetramethyl tetraaryl calix[4]pyrroles 
Another appealing way whereby changes in structure could be used to modulate the basic anion binding properties of a given calix[4]pyrrole is via the covalent imposition of a preorganized binding site. An example of this approach is embodied in the strapped calixpyrroles 14 and 15 . These systems, which were prepared by condensing pyrrole with the appropriate "pre-strapped" diketones, are rather unique in that they contain either ancillary "cryptand-like" binding sites for a counter cation (system 14) or additional, amide-derived $\mathrm{NH}$ hydrogen bond donor functionality (system 15). In either case, enhanced anion binding affinities and/or ion pair selectivities might be expected.

A very different kind of preorganized system is defined by compounds 16 and 17 . These heterodimers were obtained as the

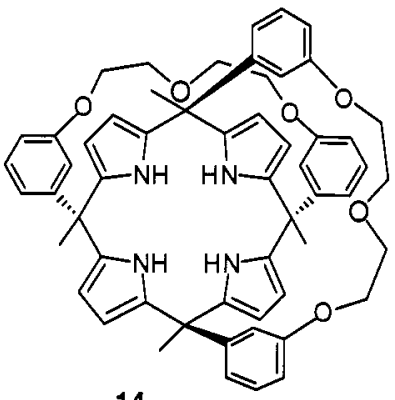
14

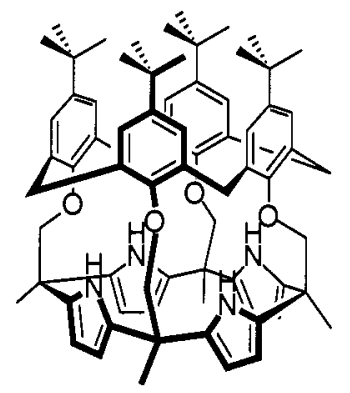

16
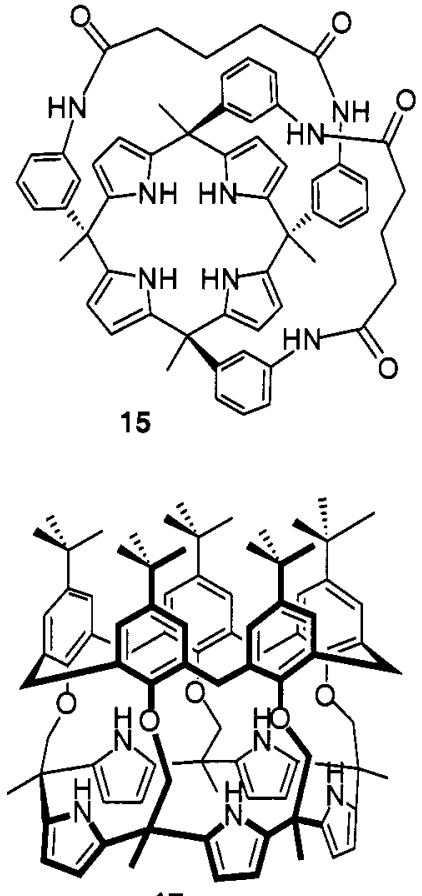

17 result of a template mediated condensation between a keto-functionalized calixarene and pyrrole and define, respectively, the first calixpyrrole-calixarene conjugate ${ }^{15}$ and first expanded calixpyrrole (i.e., a calix[n]pyrrole with $n>4)^{16}$ to be recorded in the literature.

\section{Products from Mixed Condensations}

The high yields that are obtained in the course of simple single pyrrole plus single ketone condensations, makes it possible to conceive of preparing modified calixpyrroles via the condensation of more than one ketone with a single pyrrole or more than one pyrrole with a single ketone (as well as from condensations involving more complex mixtures). To date, it is the first of these strategies that has been most extensively explored. In particular, methyl 5-oxopentanoate was co-condensed with cyclohexanone to produce, after saponification and reprotonation, the meso-carboxyl functionalized calixpyrrole $\mathbf{1 8 . 1 7}$ As discussed below, this product has proved to be a very useful intermediate in the synthesis of other functionalized calix[4]pyrroles. It is also of interest in and of its own right in that it undergoes selfassembly in both $\mathrm{CD}_{2} \mathrm{Cl}_{2}$ solution and in the solid state. ${ }^{17}$

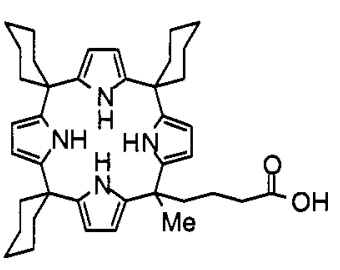

18

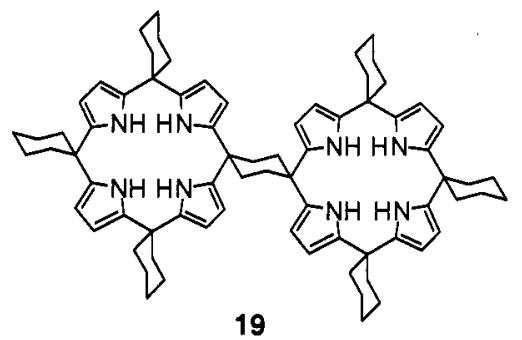

19

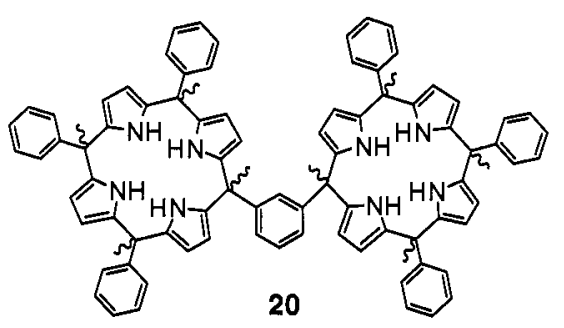

20

Mixed condensation strategies have also been employed recently to prepare the calix[4]pyrrole dimers 19 and 20. Based on preliminary studies with diols and dicarboxylate anions, these systems show promise as acting as cooperative homoditopic anion and neutral substrate receptors (Fig. 2). 

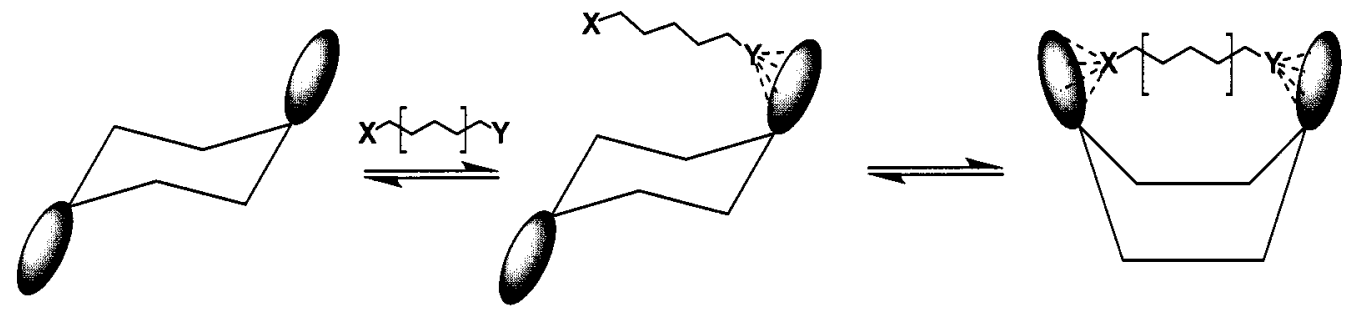

Figure 2. Proposed model of cooperative difunctional substrate binding by ditopic receptors $\mathbf{1 9}$ and $\mathbf{2 0}$.

\section{CALIXPYRROLES OBTAINED VLA POST-MACROCYCLIZATION MODIFICATIONS}

\section{Products from Direct One-pot Reactions}

Pyrroles are known to be rather electron rich as compared to benzene. As a general rule, therefore, they react well with electrophiles. It was thus considered possible that the key electron poor analogue of 3 , namely the octabromo derivative 21, might be obtainable via the direct reaction of 1 with NBS. In fact, this transformation worked as envisioned, with a $90 \%$ yield of 21 being obtained in this way. ${ }^{14}$ Further, as expected, this particular calix[4]pyrrole proved to be an anion receptor par excellence, displaying anion affinities that were upwards of an order of magnitude larger than $\mathbf{1}$ and upwards of two orders of magnitude larger than $3 .^{10}$

Related chemistry, involving treatment of 1 with $\mathrm{n}$-BuLi followed by treatment with ethyl bromoacetate, gave (after saponification and reprotonation), the mono acetic acid 22 or, in the case where $\mathrm{CO}_{2}$ was used, the directly substituted system 23. The use of $\mathrm{ICl}$ as the electrophile in these kinds of reactions has also permitted the isolation of the monoiodo calix[4]pyrrole 24. In all cases, it is possible to isolate doubly functionalized (or even more fully substituted) by-products; however, these have proved easy to<smiles>CC(C)(C)c1[nH]c(C(C)(C)c2[nH]c(C(C)(C)c3[nH]c(C(C)(C)c4[nH]c(C(C)(C)c5[nH]c(C(C)(C)C)c(Br)c5Br)c(Br)c4Br)c(Br)c3Br)c(Br)c2Br)c(Br)c1Br</smiles>

21

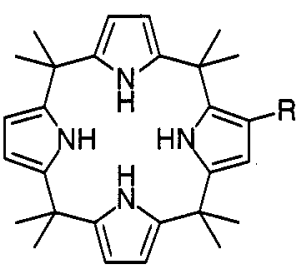

22. $\mathrm{R}=\mathrm{CH}_{2} \mathrm{CO}_{2} \mathrm{H}$

23. $\mathrm{R}=\mathrm{CO}_{2} \mathrm{H}$

24. $R=1$ remove via column chromatography.

\section{Calix[4]pyrrole Conjugates}

\section{Mononuclear Materials}

With suitably functionalized systems, notably calix[4]pyrroles $\mathbf{1 8}, \mathbf{2 2 - 2 4}$, in hand, a library-like construction of calixpyrrole conjugates becomes possible. Structures 25-35 are representative of some of the systems we have prepared to date. With the exception of the anthracene functionalized calixpyrrole 35, which was obtained using organometallic coupling methods, all were prepared via the reaction of an activated calix[4]pyrrole acid (i.e., 18, 22 or 23) with an amine. In spite of this, the resulting amide-linked systems were found to display rather disparate properties. For instance, compounds $\mathbf{2 5}$ and $\mathbf{2 6}$ incorporate glucosamide residues and are appreciably water soluble. By contrast, the crown ether derivative $\mathbf{2 7}$ is not water soluble. However, by virtue of containing a built-in cation binding site, it could prove useful in either extracting salt mixtures out of water or allowing for the enhanced through-membrane transport of ion pairs or zwitterions. The cytosine-linked calix[4]pyrroles 28 and 29 also show promise as selective transport agents for guanine-containing nucleotides. Indeed, it has recently been found that the meso-linked conjugate 28 (but not its $\beta$-linked congener 29) acts as a selective carrier for GMP in a Utube type Aqueous I - $\mathrm{CH}_{2} \mathrm{Cl}_{2}$ - Aqueous II model membrane system (Figs. 3 and 4). 


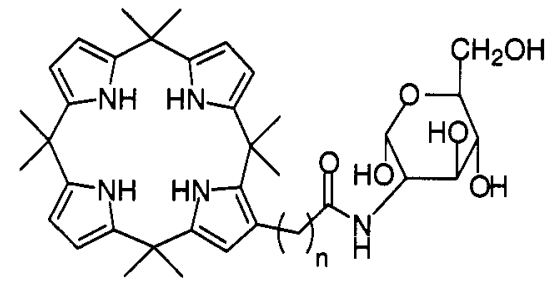

25. $n=1$

26. $n=0$

Callxpyrrole-cytosine conjugate (meso-linked)

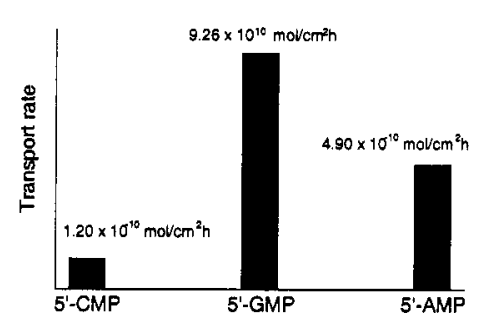

Figure 3. Nucleotide transport rates for 28.

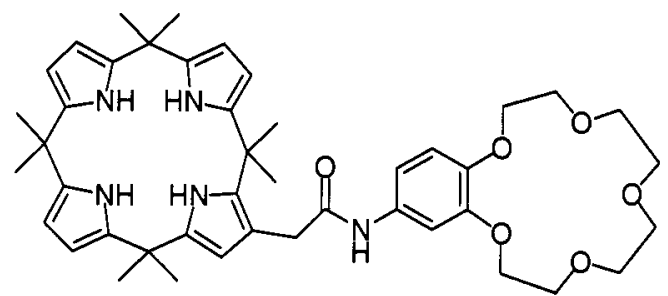

27

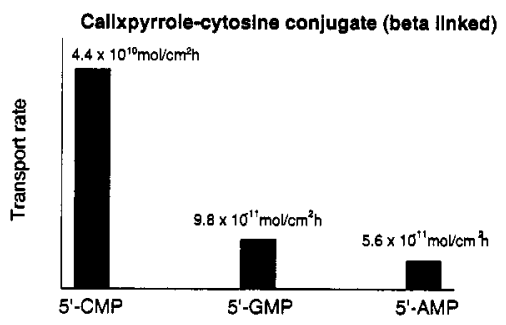

Figure 4. Nucleotide transport rates for 29.

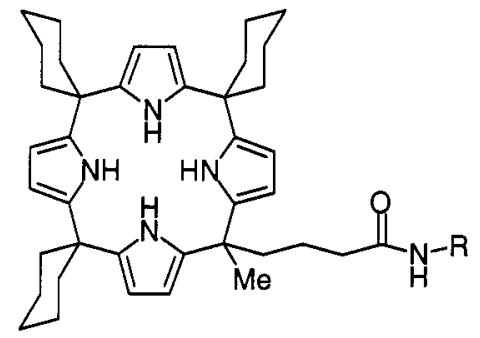

28. $R=A$

30. $R=B$

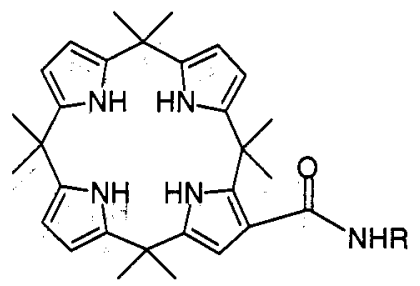

32. $R=A$

33. $R=B$

34. $R=C$

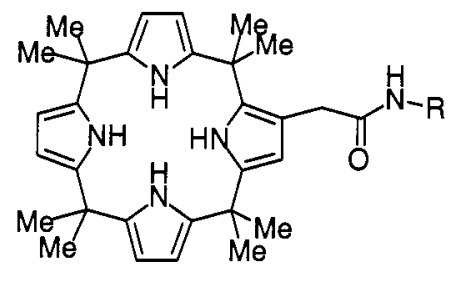

29. $R=A$

31. $R=B$<smiles>NC1=NC([O])N(CCC#[Tl])C=C1</smiles>

$\mathrm{B}=$<smiles></smiles><smiles>[B]=C=C1N=c2ccccc2=C(C)c2ccccc21</smiles><smiles></smiles> 
Conjugates 30 and 31 are of special interest in that they incorporate ferrocene centers. ${ }^{18}$ This redox active moiety is one that has been extensively studied in the context of preparing electrochemical sensors for various small molecule analytes. ${ }^{2}$ Its attachment to calix[4]pyrrole is allowing anion binding events to be studied in this way.

Another way of allowing anionic analytes to be probed is through the attachment of a fluorescent chromophore to the calix[4]pyrrole skeleton as has been done in the case of conjugates 32-35. In this case, as has been demonstrated in preliminary work with 32, addition of an anion (tetrabutylammonium chloride in the case of 32) leads to a quenching of the flourophore emission (Fig. 5). Given the ease of synthesis and the unique anion binding characteristics of the calixpyrroles, this approach to anion sensing appears to hold great promise.

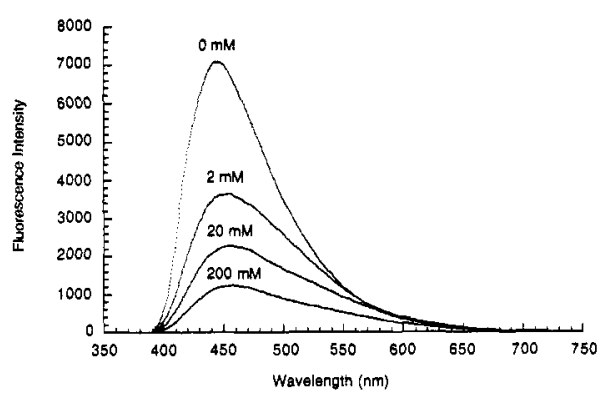

Figure 5. Fluorescence spectra of calixpyrrole 32 in $\mathrm{CH}_{2} \mathrm{Cl}_{2}$ showing the changes induced upon the addition of increasing quantities of tetrabutylammonium chloride $\left(\lambda_{\text {excit. }}=378 \mathrm{~nm}\right)$.

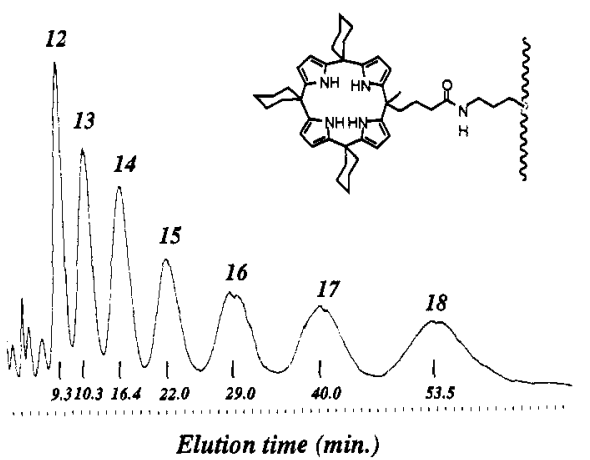

Figure 6. Separation of $\mathrm{dT}_{12-18}$ on a calixpyrrole modified silica gel column. Eluent: $50 / 50 \quad \mathrm{CH}_{3} \mathrm{CN} /$ aqueous $(250 \mathrm{mM}$ $\left.\mathrm{NaCl}+50 \mathrm{mM} \mathrm{NaH}_{2} \mathrm{PO}_{4}\right), \mathrm{pH} 7.0,25^{\circ} \mathrm{C}$.

\section{Functionalized Solid Supports}

A very different way of exploiting the availability of carboxyl-functionalized calixpyrroles is to use them to prepare modified solid supports. In principle, such supports could be used to help effect the remediative removal of anionic wastes from industrial, agricultural, or radioactive sources. They could also be used as stationary phases to effect the chromatography-based purifications of anionic substrates. To date, it has been this latter opportunity that we have focused on exploring most extensively. Indeed, we have prepared several calixpyrrole-functionalized silica gels and found that they work to effect the separation of inter alia oligonucleotides under conditions of isochratic aqueous acetonitrile elution (Fig. 6). ${ }^{6}$
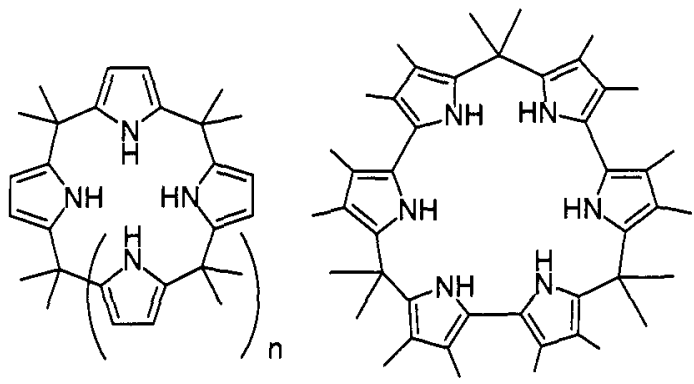

36. $n=5$

37. $n=6$

38. $n=7$

39. $n=8$

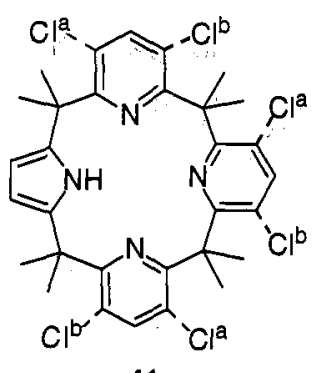

41

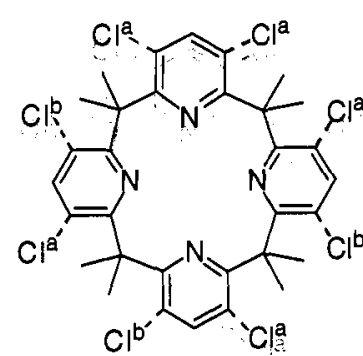

42

Note: In structures $\mathbf{4 1}$ and $\mathbf{4 2}$ the chlorine atoms are located in positions "a" or "b" but not in both. 


\section{CONCLUSION AND FUTURE DIRECTIONS}

The rather new nature of the calixpyrroles, coupled with their ease of synthesis and versatility in terms of modification leads us to suggest that this class of anion receptors will emerge as being particularly useful in a range of recognition and transport applications, including possibly those associated with biological analyte sensing, antiviral drug delivery, and out-of-cell chloride anion transport. On the synthetic front, clearly a lot remains to be done since a seemingly infinite number of modified calixpyrrole targets seem easy to conceive. Other obvious directions involve preparing higher order calix[n]pyrrole products $(n>4)$, using bipyrroles (or related entities) to replace pyrrole in the key calixpyrrole-forming pyrrole-plus-acetone condensations, and using calix[4]pyrroles as "starting materials" in further synthetic transformations. In preliminary work, involving the use of $\mathrm{BF}_{3} \cdot \mathrm{Et}_{2} \mathrm{O}$ as the acid catalyst, we have succeeded in preparing, but not yet isolating cleanly, the calix[n]pyrroles 36-39 as well as the bipyrrolederived product 40 . On a separate front, we have also found that calix[4]pyrroles react with dichlorocarbenes readily to generate calix[n]pyridino[m]pyrroles such as $\mathbf{4 1}$ and $\mathbf{4 2}$, the existence of which has been unambiguously established via X-ray crystallographic analysis. ${ }^{19}$ Thus, it is clear that the field of calixpyrrole chemistry, although still in its modern era infancy, is ripe for further rapid development.

\section{ACKNOWLEDGMENTS}

This work was supported by the National Institutes of Health (AI 33577 and TW 00682 to J.L.S.), the National Science Foundation (CHE-9725399 to J.L.S.), the Howard Hughes Foundation (V.K. and J.L.S.), a Royal Society University Research Fellowship (to P.A.G.), and the Grant Agency and Ministry of Education of the Czech Republic (grants 203/96/0740, 203/97/1099 and VF 97135 to V.K.).

\section{REFERENCES}

1. A. P. de Silva, H. Q. N. Gunaratne, T. Gunnlaugsson, A. J. M. Huxley, C. P. McCoy, J. T. Rademacher, T. E. Rice. Chem. Rev. 97, 1515 (1997).

2. P. D. Beer. Chem. Commun. 689 (1996).

3. Y. Umezawa, M. Sugawara, M. Kataoka, K. Odashima. In Ion-Selective Electrodes, 5th Ed. (E. Pugor, ed.), pp 211-234. Akadémiai Kiadó (Pergamon Press), Budapest (Oxford), 1989.

4. P. D. Beer, D. K. Smith. Prog. Inorg. Chem. 46, 1 (1997).

5. C. E. Kibbey, M. E. Meyerhoff. Anal. Chem. 65, 2189 (1993).

6. J. L. Sessler, P. A. Gale, J. W. Genge. Chem. Eur. J. 4, 1095 (1998).

7. J. L. Sessler, P. I. Sansom, A. Andrievsky, V. Král. In Supramolecular Chemistry of Anions (A. Bianchi, K. Bowman-James, E. Garcia-Espana, eds.), pp 355-419. VCH Verlag, Weinheim (1997).

8. M. El-Etri, J. Cuppoletti. Am. J. Physiol. 270, L386 (1996).

9. F. P. Schmidtchen, M. Berger. Chem. Rev. 97, 1609 (1997).

10. P. A. Gale, J. L. Sessler, V. Král. Chem. Commun. 1 (1998).

11. A. Baeyer. Ber. Dtsch. Chem. Ges. 19, 2184 (1886).

12. P. A. Gale, J. L. Sessler, V. Král, V. Lynch. J. Am. Chem. Soc. 118, 5140 (1996).

13. W. E. Allen, P. A. Gale, C. T. Brown, V. Lynch, J. L. Sessler. J. Am. Chem. Soc. 118, 12471 (1996).

14. P. A. Gale, J. L. Sessler, W. E. Allen, N. A. Tvermoes, V. Lynch. Chem. Commun. 665 (1997).

15. P. A. Gale, J. L. Sessler, V. Lynch, P. I. Sansom. Tetrahedron Lett. 37, 7881 (1996).

16. P. A. Gale, J. W. Genge, V. Král, M. A. McKervey, J. L. Sessler, A. Walker. Tetrahedron Lett. 38, 8443 (1997).

17. J. L. Sessler, A. Andrievsky, P. A. Gale, V. Lynch. Angew. Chem. Int. Ed. Engl. 35, 2782 (1996).

18. J. L. Sessler, A. Gebauer, P. A. Gale. Gaz. Chim. Ital. 127, 723 (1997).

19. V. Král, P. A. Gale, P. Anzenbacher, Jr., K. Jusiková, V. Lynch, J. L. Sessler. Chem. Commun. 9 (1998). 